\title{
Analysis on the Driving Forces for the Change of Agricultural Structure in China Yongliang Zhao ${ }^{1, \text { a }}$ \\ ${ }^{1}$ China industrial economic security research center, Beijing , 10044 , China \\ azhaoyongliang@126.com
}

Keywords: Agricultural structure, Historic changes, Driving forces

\begin{abstract}
This paper summarizes the driving functions of natural, economic and social factors on the historic changes of the agricultural structure. Generally, natural and ecological factors (such as climate and environment) and social and economic factors (such as markets and policies) play the dominant role in the natural economy and the commodity economy respectively for the change of agricultural structure. Faced with pressures from the environment and resources nowadays, ecological value of agriculture will inevitably serve as an important guideline for agricultural structure adjustment in future.
\end{abstract}

\section{Introduction}

Agriculture is based on natural ecosystems and at the same time with social and economic investment as premise. Agricultural structure is a general term referring to various structures within the agricultural system, including sub-systems, biotic components, internal ecological and economic relationships, etc. Agriculture system is a typical complex system featuring nature-society-economy. Therefore, it can be both ecologically and economically defined[1]. According to the ecological definition, agricultural ecological structure, centering on agricultural lives, refers to the species structure, space structure, time structure and food chain structure, which are based on the allocation of components in the agricultural ecosystem in space and time and the order of energy substance flow among these components. According to the economic definition, agricultural economic structure refers to the layout of such links in the social reproduction process as production, distribution, exchange, consumption, etc., and the input-output relationship [2]. With the allocation of economic factors as standards, agricultural structure can be divided into agricultural input structure and agricultural output structure. The literal meanings of the two definitions differ greatly; but from the perspective of agricultural structure adjustment, agricultural structure actually refers to the outward manifestations of agricultural ecological structure driven by the agricultural economic structure. The interaction of the agricultural ecosystem and economic system constitutes an intact and complex agriculture structure.

\section{Influence of natural environment and resource conditions on agricultural structure}

\subsection{Climate is the determining factor of agricultural species structure}

Take the Yellow River Basin, cradle of the Chinese civilization, as an example. The climate in the southeast Shandong Province and Lianyungang 4000 years ago was warm and moist, which helped form the planting structure with rice as major plants and grain and millet as minor plants. Later, with the climate turning drier and colder, wheat gradually replaced rice as the major plants and the cash crop cotton was not widely cultivated until the Ming and Qing Dynasties [3]. Since the Ming and Qing Dynasties, with the climate warming, natural disasters such as drought, flood, frost and snow, and sand, etc. hit the northwest China frequently, and water resources were strained, which promoted the surge of the planting area of drought tolerant cash crops such as corn, sweet potato, potato, etc., and the transitional zone from cropland to grassland moved northward. Therefore, it becomes important empirical experiences to adjust agricultural structure according to climate changes, phonological features and seasons. Even today, some regions would adjust agriculture structure based on climate changes. 


\subsection{Water and land resources are basic conditions of agricultural production structure}

For example, the hilly landscape of the Mongolian Plateau determines an agricultural structure with animal husbandry playing a major role and planting industry a minor role. Changes in landscape, soil and water resources also promote adjustment of agricultural production structure. It was not until the Ming Dynasty that new improvements emerged: one was the reclamation of terraces, where rice, wheat, and corns, etc. were cultivated with full use of water resources; the other one was the utilization of sloping fields for the planting of cash trees such as cedars, mulberries, and varnish trees, etc., which were interplant with wheat and corn, forming the stereo-agricultural structure with pine trees on the top of mountains, tung trees halfway up the mountains, and willows alongside the rivers and ponds. The historic changes of stereo-agricultural structure in the regions where Tujia people inhabit in the southwest Hubei Province show the expansion of agricultural production from the river valleys to mountains resulted from the changes of agricultural resources and conditions. At the same time, the improvement in the agricultural environment in small regions will facilitate structural adjustment of agriculture. In recent years, the deterioration of agricultural resources and conditions, such as agricultural land reduction, water resources shortage and environmental pollution, has constituted the major causes for compulsory changes of agricultural layout and species structure in many regions.

\section{Influence of economic laws and market demands on agricultural structure}

\subsection{Internal demands from the produce markets}

Studies indicate that, with produce demand expansion driven by the increase of population since the Ming Dynasty, major changes in the plantation structure took place: triple cropping system in two years of wheat, constant expansion of high yield crops (such as rice, grain, corn and sweet potato) with good adaptability, cash crops (cotton, peanuts, tobacco and fruit trees instead of mulberries and sesames) becoming the major cash crops [4]. The development of commodity economy in modern China (from the 1850s to the 1950s) further advanced sustainable increase of total output of crops and the proportion of cash crops. Compared with the conventional closed and self-sufficient production mode, agricultural structure is more diverse.

\subsection{Stimulus from the open markets}

Since the late 1800s, China had gradually opened its door to the outside world. The open markets had stimulated the changes in agricultural structure. For instance, after Jiujiang opened the port, cash crops such as tea, cotton and oil crops were exported to the world agricultural markets. And the plantation area of these crops in Jiujiang expanded rapidly, accelerating the structural change of agricultural production in Jiangxi Province [23]. Meanwhile, many good livestock were imported successively into modern China so as to improve traditional varieties of livestock, including pigs, horses, cows, sheep, chicken, and ducks, etc., thus laying foundation for China's modern husbandry species structure. The impact on agricultural structure from the open markets is fundamental. Therefore, consequent changes happened to the agricultural industry structure, regional structure and social structure of China.

\subsection{Economic benefits become the determining factor.}

After agriculture became an industry under complete market economy condition, market laws were the most important factors that determine the changes of agricultural structure. Since the reform and opening up, the agricultural structure of the Wuxian City, Jiangsu Province in the Yangtze River Delta has changed sharply. Within the plantation industry, land planted with rice and wheat was reduced while planting area for vegetables and aquatic cash plants increased; within the aquaculture, man-made fishing ponds were expanded; fish of high-value and special aquaculture including shrimps, crabs, soft-shelled turtles, and pearls, etc., were cultivated in large quantity; less pigs and more poultry and livestock feeding on grass such as cows and sheep were raised for better economic benefits. Due to the fluctuation of produce markets, the ratio between plantation industry and aquaculture also changes frequently in recent years. In Shangrao County, Jiangxi Province, the earnings difference per unit land area resulted from the changes of produce prices also promoted the 
transformation between arable land, garden plots and waters. Economic benefits have become the major driving force for structural adjustment of agriculture.

\section{Influence of social and policy factors on agriculture structure}

\subsection{Size of agricultural population}

In ancient China, the group living style required that a larger size of population was to raise per unit field. Influence by the multiple inheritance system, the agricultural production scale became smaller and smaller. Therefore, it was impossible for China to attach the same importance to the plantation industry and aquaculture like Europe, and the agricultural structure can only be dominated by the plantation industry [28]. However, since the implementation of the family planning policy in the 1970s, agricultural production efficiency and produce output have seen major improvement. And population growth does not exceed the grain output increase. Therefore, constraints from population growth on agriculture development reduce and population size plays a less important role on agricultural structure.

\subsection{Food consumption structures}

There are three phases for the changes in the living standards of Chinese residents, namely food and clothing, moderate prosperity and wealth. And produce consumption structure changes accordingly. An analysis on the food consumption structure of urban and rural residents in the Yangtze River Delta indicates that the consumption proportions of pork, beef and mutton, poultry products, and aquatic products among urban and rural residents are $1 / 3,1 / 3$ and $1 / 3$. The change in consumption trend becomes the fundamental reason for the adjustment of agricultural production structure.

\subsection{Agricultural management policies}

Before the agricultural reform in 1978, China adopted a planned economy system, which partially focused on the growth of grain output, resulting in a single and grain-oriented agricultural structure. After reform and opening up, many regions adopted market-oriented agricultural management policies. But the difference in policy efficiency also resulted in different agricultural structure. Comparing the changes of agricultural structures from 1981 to 2002 between Guangdong Province and Hebei Province, we can find that both the types and structures of types in the two provinces develop in diverse directions; however, the structure of grain crops of Guangdong Province develops diversely while that of Hebei Province develops in the singular directione.

\section{Ecological and environmental functions become the guiding principle for current adjustment of agricultural structure}

\subsection{Attach importance to the ecological construction in ecologically vulnerable areas}

Although the economic and social benefits have been achieved with the development of agricultural resources, the ecological consequences neglected has gradually drawn wide attention. The south Hunan Province had long been a land of honey and milk. However, with the increase of population and expansion of agricultural development since the Ming and Qing Dynasties, ecological environment gradually degraded and drought and flood happened frequently. At present, ecological construction has become one of the major goals for adjustment of agricultural structure [5]. Similarly, predatory conducts over the Inner Mongolian grassland in modern times had sacrificed the natural environment and aggravated the desertification there. Now it is the inevitable choice to return farmland to grassland, and adopt rest-rotation grazing so as to build a picturesque Erdos. We should also follow the ecological laws to optimize existing agricultural structure in other ecologically vulnerable areas.

\subsection{Promote ecological planning of suburban agriculture}

With the enhancement of ecological awareness in society, it should be the basic principles for current adjustment of agricultural structure to take the laws of natural ecology as the basis, create sound ecological environment, emphasize harmony between human and nature, and conserve resources. Nowadays, the number and size of cities are expanding and the scope of suburban 
agriculture is also enlarging. People's demand for ecological adjustment and entertainment functions of agriculture even outweighs its production capacity. Thus, it becomes the new driving force for the structural adjustment of suburban agriculture by emphasizing its ecological functions. New agricultural structure modes, including establishing nature conservations, ecological conservation areas, complex production areas of agriculture and forestry, sightseeing tourist sites, are theoretically brought about. In practices, ecological planning and design has become the fundamental work for structural adjustment of agriculture in some areas in recent years.

\section{Discussion}

In conclusion, the synergistic effects of multiple complex factors become the driving forces for the historic changes of the agricultural structure. Generally, natural and ecological factors (such as climate and environment) and social and economic factors (such as markets and policies) play the dominant role in the natural economy and the commodity economy respectively for the change of agricultural structure. Recent studies on the driving forces for changes in the utilization of suburban land also show that natural environment is the basic condition while social, economic and technological factors play decisive roles. Faced with pressure from environment and resources today, to realize sustainable development of agriculture, we must follow ecological laws, and explore ecological functions of agriculture. Ecological value of agriculture will inevitably serve as an important guideline for agricultural structure adjustment in future. In contrast, owing to the fact the multifunctionality of agriculture, such as landscape maintenance, biodiversity, and cultural heritage has been fully realized, the cross-compliant measures between production and environment in the common agriculture policy (CAP) have become major driving forces for the adjustment of agricultural structure. Therefore, it is worth in-depth analysis on the causality between different agricultural ecosystem structures and ecological functions of agriculture, as well as the synergistic relationship between economic and ecological values of agriculture.

\section{References}

[1]Lu Bu,Chen Yinjun, Wu Kai. The present situation and future trends of agriculture structure in China. Agricultural technology and economy, Vol. 62 (2008) No. 2,p.52- 57

[2] Ye Shaoyin. The research on agricultural structure, function change and sustainable development ([D]. Fujian Agriculture and Forestry University,China, 2001).p.22-23

[3] Gao Huazhong. Study on the planting structure of agriculture Archaeology of Longshan culture period in the southeast of Shandong , Vol. 31 (2006) No. 1,p.23-26

[4] Chen Dongsheng. The Shandong planting structure changes and the impact on agriculture and agricultural in Ming and Qing Dynasties ,Vol. 36 (2001) No. 2,p.44-59

[5] Yang Zaitian, Zhong Shunqing. The Hunan agricultural development and the change of ecological environment in historical period . Hengyang Normal University: Natural Science Edition, Vol. 22 (2001) No. 6,p. 69 - 74 